\title{
Epidemic Peaks Forecasting on Re-emerging Diseases in Elderly People using the Grey Disaster Model
}

\author{
Nipaporn Chutiman ${ }^{1}$, Pannarat Guayjarernpanishk ${ }^{2}$, Butsakorn Kong-ied ${ }^{1}$, \\ Piyapatr Busababodhin ${ }^{1}$, Monchaya Chiangpradit ${ }^{1 *}$ \\ ${ }^{1}$ Data Science and Sustainable Agriculture Research Unit, Department of Mathematics, Faculty of Science, Mahasarakham University, \\ Maha Sarakham 41150, Thailand \\ ${ }^{2}$ Faculty of Interdisciplinary Studies, Nong Khai Campus, Khon Kaen University, Nong Khai 43000, Thailand
}

\begin{abstract}
Climate change causes the spread of non-vector diseases due to the influence of climate uncertainty. The elderly group, which is vulnerable, is affected by such disasters. Therefore, the objectives of this study were to forecast epidemic peaks of food poisoning, which was found as one of the re-emerging diseases in elderly people in Khon Kaen Province, Maha Sarakham Province, and Roi Et Province, which are in the Northeastern region of Thailand by using 2 types of Grey Model: GM(1,1) and Discrete Grey Model (DGM). The monthly rate of food poisoning incidence per 100,000 elderly people from January 2017 to December 2020 i.e., 48 months in total were used in the study. The study result revealed that the DGM had higher forecasting effectiveness than that of the $\operatorname{GM}(1,1)$ in all three provinces. The food poisoning incidences in elderly people were forecasted to re-emerge from August to September 2021 in Khon Kaen Province, from August to September 2022 in Maha Sarakham Province, and from May to June 2022 in Roi Et Province. The results of this study are useful and helpful for the government, the Ministry of Public Health and related cooperatives to effectively help services planning resource preparation and prevention measures.
\end{abstract}

\section{Keywords:}

Epidemic Peaks;

Grey Disaster Model;

Re-emerging Diseases;

$\mathrm{GM}(1,1)$.

Article History:

Received: 08 August 2021

Revised: $\quad 15 \quad$ October 2021

Accepted: 03 November 2021

Published: $01 \quad$ December 2021

\section{1- Introduction}

Climate change causes seasonal infectious diseases due to the influence of climate uncertainty such as temperature and humidity as parts of climate variation. Moreover, the spread of non-vector diseases such as diarrhea and food poisoning is sometimes affected by climate change. The population structure of Thailand has changed into an aging society. In 2020, the northeastern region contained the largest number of elderly people. According to the Ministry of Social Development and Human Security, the number of elderly people at the age of 60 years upward in the next 20 years is estimated to increase up to $30 \%$.

The forecasting of diseases and health threats is very important because the forecasting results allow surveillance on epidemiological diseases for the benefits of resource planning, and disease prevention and treatments in an effective way. Ju-Long $(1982,1989)$ [1-2] presents the Grey Model or GM(1,1) by basing the study principles on discrete data, uncertainty data distribution, and the limited number of data. The theory of $\operatorname{GM}(1,1)$ is widely used. In addition, Xie and Liu (2008) [3] develop the Discrete Grey Model (DGM) from the effective improvement of the GM(1,1). The models

\footnotetext{
*CONTACT: monchaya.c@msu.ac.th
}

DOI: http://dx.doi.org/10.28991/esj-2021-01325

(C) 2021 by the authors. Licensee ESJ, Italy. This is an open access article under the terms and conditions of the Creative Commons Attribution (CC-BY) license (https://creativecommons.org/licenses/by/4.0/). 
are widely used in medicines [4-9], and other areas such as petroleum, geological engineering, industry, management, marketing, and agriculture [10-23]. In medicines and public health, the spread of diseases is affected by several uncertain factors, so the Grey theory with dynamic changes is suitable to be used. The $\operatorname{GM}(1,1)$ is popularly used in forecasting diseases and death rates from epidemics. As a result, this research studied the epidemic peaks of food poisoning of elderly people in Khon Kaen Province, Maha Sarakham Province, and Roi Et Province (Thailand) since those provinces were almost in the top ranks of elderly people with food poisoning in the middle northeastern region. The analyses with $\mathrm{GM}(1,1)$ and DGM are useful for planning resources and preventing the diseases effectively.

\section{2- Data Preparation and Methodology}

\section{2-1- Data}

The data in this research were the monthly rate of food poisoning incidence per 100,000 elderly people from January 2017 - December 2020 i.e., 48 months in total in Khon Kaen Province, Maha Sarakham Province, and Roi Et Province.

\section{2-2- $G M(1,1)$}

GM(1,1) is the model of the Grey theory of prediction with one variable .The first order Grey model is created with a few data (four or more .(Its procedure is as follows:

- The existing data with the $n$ sample units are represented in $X^{(0)}=\left(x^{(0)}(1), x^{(0)}(2), \ldots, x^{(0)}(n)\right)$, where $X^{(0)}$ is the series of data.

- Calculate the cumulative sum of the existing data $X^{(0)}$ in the form of a cumulative sum series.

$X^{(1)}=\left(x^{(1)}(1), x^{(1)}(2), \ldots, x^{(1)}(n)\right)=\left(\sum_{i=1}^{1} x^{(0)}(i), \sum_{i=1}^{2} x^{(0)}(i), \ldots, \sum_{i=1}^{n} x^{(0)}(i)\right)$.

- Calculate $Z^{(1)}$, the means from (1) as:

$Z^{(1)}=\left(z^{(1)}(2), z^{(1)}(3), \ldots, z^{(1)}(n)\right)$,

where $z^{(1)}(k)=0.5 x^{(1)}(k)+0.5 x^{(1)}(k-1) ; k=2,3, \ldots, n$.

- Calculate for the differential equation of $\operatorname{GM}(1,1)$ with $\frac{d x^{(1)}}{d t}+a x^{(1)}=b$.

The resulting derivative of a function is $x^{(0)}(k)+a z^{(1)}(k)=b$ where $a$ and $b$ are the parameters of $\operatorname{GM}(1,1)$.

That is, $\left[\begin{array}{ll}a & b\end{array}\right]^{T}=\left(B^{T} B\right)^{-1} B^{T} Y$,

where $Y=\left[\begin{array}{c}x^{(0)}(2) \\ x^{(0)}(3) \\ \vdots \\ x^{(0)}(n)\end{array}\right]$ and $B=\left[\begin{array}{cc}-z^{(1)}(2) & 1 \\ -z^{(1)}(3) & 1 \\ \vdots & \vdots \\ -z^{(1)}(n) & 1\end{array}\right]$.

- The forecasting equation can be calculated by;

$\hat{x}^{(1)}(k+1)=\left(x^{(0)}(1)-\frac{b}{a}\right) e^{-a k}+\frac{b}{a}$.

And the new equation is adjusted as follows:

$$
\hat{x}^{(0)}(k+1)=\hat{x}^{(1)}(k+1)-\hat{x}^{(1)}(k)=\left(1-e^{a}\right)\left(x^{(0)}(1)-\frac{b}{a}\right) e^{-a k} .
$$

It is called the time response equation.

\section{2-3-Discrete Grey Model (DGM)}

The DGM procedure is as follows:

- The equation $x^{(1)}(k+1)=\beta_{1} x^{(1)}(k)+\beta_{2}$ 
It is called the Discrete Grey Model (DGM).

- $\hat{\beta}=\left(\begin{array}{ll}\beta_{1} & \beta_{2}\end{array}\right)^{T}$ is the series of parameters where $Y=\left[\begin{array}{c}x^{(1)}(2) \\ x^{(1)}(3) \\ \vdots \\ x^{(1)} n\end{array}\right]$ and $B=\left[\begin{array}{cc}x^{(1)}(1) & 1 \\ x^{(1)}(2) & 1 \\ \vdots & \vdots \\ x^{(1)}(n-1) & 1\end{array}\right]$.

The least square method is used to estimate the parameters in the equation:

$\hat{x}^{(1)}(k+1)=\beta_{1} x^{(1)}(k)+\beta_{2}$,

where $\hat{\beta}=\left(B^{T} B\right)^{-1} B^{T} Y$.

- Let $x^{(1)}(1)=x^{(0)}(1)$, then the recursive function is used with the following setting:

$\hat{x}^{(1)}(k+1)=\beta_{1}^{k} x^{(0)}(1)+\frac{1-\beta_{1}^{k}}{1-\beta_{1}} \times \beta_{2}$,

or $\hat{x}^{(1)}(k+1)=\beta_{1}^{k}\left(x^{(0)}(1)-\frac{\beta_{2}}{1-\beta_{1}}\right)+\frac{\beta_{2}}{1-\beta_{1}}$,

where $k=1,2, \ldots, n-1$.

Then restore the value of $\hat{x}^{(0)}(k)$, and the forecasting equation of DGM is obtained as follows:

$\hat{x}^{(0)}(k+1)=\alpha^{(1)} \hat{x}^{(1)}(k+1)=\hat{x}^{(1)}(k+1)-\hat{x}^{(1)}(k)$,

where $k=1,2, \ldots, n-1$.

\section{2-4- Model Accuracy Test}

The model accuracy tests are as follows;

- Mean Relative Error

$\bar{\Delta}=\frac{1}{n-1} \sum_{k=2}^{n} \Delta_{k}=\frac{1}{n-1} \sum_{k=2}^{n}\left|\frac{\varepsilon(k)}{x^{(0)}(k)}\right|$.

For the given $\alpha$, when $\bar{\Delta}<\alpha$ and $\Delta_{n}<\alpha$ are true, the forecasting model is regarded as satisfied.

- Absolute Degree of Incidence;

$\varepsilon=\frac{1+\left|s_{0}\right|+\left|s_{i}\right|}{1+\left|s_{0}\right|+\left|s_{i}\right|+\left|s_{i}-s_{0}\right|}$,

where $\left|s_{0}\right|=\left|\sum_{k=2}^{n-1} x_{0}^{0}(k)+\frac{1}{2} x_{0}^{0}(n)\right|$ and $\left|s_{i}\right|=\left|\sum_{k=2}^{n-1} x_{i}^{0}(k)+\frac{1}{2} x_{i}^{0}(n)\right|$.

Let $\varepsilon$ as the absolute value of the incidence level among raw data of $X^{(0)}$ and the simulated values for determining $\varepsilon_{0}>0$.If the absolute value of the incidence level is in accordance with $\varepsilon>\varepsilon_{0}$, the forecasting model is regarded as satisfied.

- Variance Ratio

$C=\frac{S_{1}}{S_{2}}=\frac{\sqrt{\frac{1}{2} \sum_{k=1}^{n}(\varepsilon(k)-\bar{\varepsilon})^{2}}}{\sqrt{\frac{1}{2} \sum_{k=1}^{n}\left(x^{(0)}(k)-\bar{x}\right)^{2}}}$.

For determining $C_{0}>0$, if the variance ratio is $C=S_{2} / S_{1}<C_{0}$, the forecasting model is considered as satisfied. 
- Small Error Probability

If $p=P\left(\mid\left(\varepsilon(k)-\bar{\varepsilon} \mid<0.6745 S_{1}\right)\right.$ is calculated for probability of small errors and for determining $p_{0}>0$;where $p>p_{0}$, the forecasting model is regarded as satisfied.

The used scale for testing the model accuracy is illustrated in Table 1.

Table 1. Scales of accuracy for model testing.

\begin{tabular}{ccccc}
\hline Accuracy scale & $\begin{array}{c}\text { Mean relative error } \\
(\bar{\Delta})\end{array}$ & $\begin{array}{c}\text { Degree of incidence } \\
(\varepsilon)\end{array}$ & $\begin{array}{c}\text { Variance ratio } \\
(c)\end{array}$ & $\begin{array}{c}\text { Small error probability } \\
(p)\end{array}$ \\
\hline $1^{\text {st }}$ level & $\leq 0.01$ & $\geq 0.90$ & $\leq 0.35$ & $\geq 0.95$ \\
$2^{\text {nd }}$ level & $0.01-0.05$ & $0.80-0.90$ & $0.35-0.50$ & $0.80-0.95$ \\
$3^{\text {rd }}$ level & $0.05-0.10$ & $0.70-0.80$ & $0.50-0.65$ & $0.70-0.80$ \\
$4^{\text {th }}$ level & $0.10-0.20$ & $0.60-0.70$ & $0.65-0.80$ & $0.60-0.70$ \\
\hline
\end{tabular}

Figure 1 shows the procedure for processing this research.

Collection of the monthly rate of food poisoning incidence per 100,000 elderly people from January 2017 - December 2020

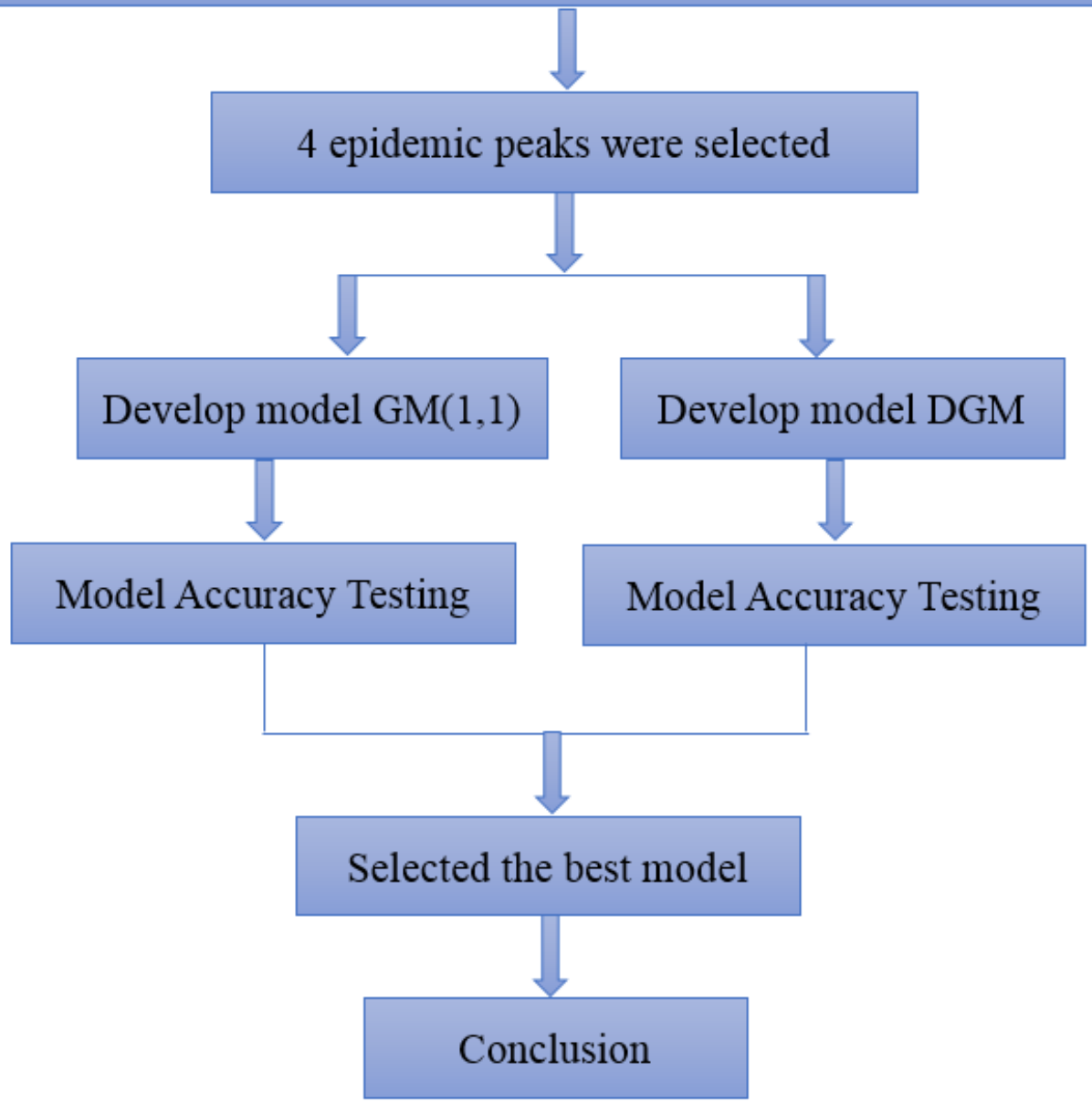

Figure 1. Flowchart of the research methodology.

\section{3- Results and Discussion}

Table 2 shows the monthly rate of food poisoning incidence per 100,000 elderly people from January 2017- December 2020 in Khon Kaen Province, Maha Sarakham Province, and Roi Et Province. The data at 4 epidemic peaks were selected for the analyses with GM(1,1) and DGM as shown in Figures 2 to 4. 
Table 2. The monthly rate of food poisoning incidence per 100,000 elderly people from January 2017 - December 2020.

\begin{tabular}{|c|c|c|c|c|c|c|c|c|c|}
\hline month-year & Time series value & $w_{1}$ & $w_{2}$ & $w_{3}$ & month-year & Time series value & $w_{1}$ & $w_{2}$ & $w_{3}$ \\
\hline Jan-17 & 1 & 88.73 & 73.39 & 106.21 & Jan-19 & 25 & 99.45 & 42.64 & 91.46 \\
\hline Feb-17 & 2 & 69.25 & 43.88 & 88.35 & Feb-19 & 26 & 76.43 & 44.03 & 59.79 \\
\hline Mar-17 & 3 & 89.78 & 55.23 & 96.07 & Mar-19 & 27 & 74.76 & 41.24 & 89.23 \\
\hline Apr-17 & 4 & 81.78 & 76.42 & 89.80 & Apr-19 & 28 & 76.09 & 46.13 & 78.08 \\
\hline May-17 & 5 & 85.60 & 77.18 & 91.25 & May-19 & 29 & 82.43 & 47.53 & 98.16 \\
\hline Jun-17 & 6 & 82.47 & 75.66 & 98.01 & Jun-19 & 30 & 87.44 & 46.13 & 109.31 \\
\hline Jul-17 & 7 & 73.42 & 89.28 & 94.63 & Jul-19 & 31 & 94.45 & 69.20 & 116.45 \\
\hline Aug-17 & 8 & 61.24 & 72.64 & 93.66 & Aug-19 & 32 & 86.77 & 60.81 & 79.86 \\
\hline Sep-17 & 9 & 68.55 & 75.66 & 113.46 & Sep-19 & 33 & 98.79 & 53.12 & 99.50 \\
\hline Oct-17 & 10 & 62.64 & 44.64 & 85.94 & Oct-19 & 34 & 72.75 & 52.42 & 94.14 \\
\hline Nov-17 & 11 & 52.89 & 46.91 & 75.32 & Nov-19 & 35 & 65.41 & 29.36 & 58.00 \\
\hline Dec-17 & 12 & 86.30 & 61.29 & 68.56 & Dec-19 & 36 & 69.08 & 34.25 & 63.80 \\
\hline Jan-18 & 13 & 85.32 & 63.39 & 91.06 & Jan-20 & 37 & 72.07 & 43.66 & 75.65 \\
\hline Feb-18 & 14 & 86.77 & 71.40 & 80.37 & Feb-20 & 38 & 60.73 & 26.19 & 66.19 \\
\hline Mar-18 & 15 & 90.11 & 49.55 & 72.47 & Mar-20 & 39 & 65.94 & 26.19 & 64.47 \\
\hline Apr-18 & 16 & 97.78 & 63.39 & 85.02 & Apr-20 & 40 & 49.38 & 22.84 & 42.98 \\
\hline May-18 & 17 & 87.10 & 68.49 & 102.67 & May-20 & 41 & 55.21 & 23.51 & 68.34 \\
\hline Jun-18 & 18 & 85.77 & 59.75 & 100.81 & Jun-20 & 42 & 66.25 & 36.94 & 86.82 \\
\hline Jul-18 & 19 & 73.09 & 74.32 & 89.20 & Jul-20 & 43 & 74.22 & 42.31 & 88.54 \\
\hline Aug-18 & 20 & 74.42 & 66.30 & 107.78 & Aug-20 & 44 & 69.01 & 52.39 & 118.63 \\
\hline Sep-18 & 21 & 76.09 & 67.76 & 101.74 & Sep-20 & 45 & 61.65 & 53.06 & 110.03 \\
\hline Oct-18 & 22 & 65.75 & 58.29 & 71.08 & Oct-20 & 46 & 38.34 & 24.18 & 71.78 \\
\hline Nov-18 & 23 & 64.08 & 51.00 & 68.29 & Nov-20 & 47 & 35.88 & 27.54 & 58.45 \\
\hline Dec-18 & 24 & 83.43 & 50.27 & 72.94 & Dec-20 & 48 & 29.75 & 33.58 & 52.01 \\
\hline
\end{tabular}

Note: $w_{1}$ is the rate of food poisoning incidence per 100,000 elderly people in Khon Kaen Province. $w_{2}$ is the rate of food poisoning incidence per 100,000 elderly people in Maha Sarakham Province. $w_{13}$ is the rate of food poisoning incidence per 100,000 elderly people in Roi Et Province.

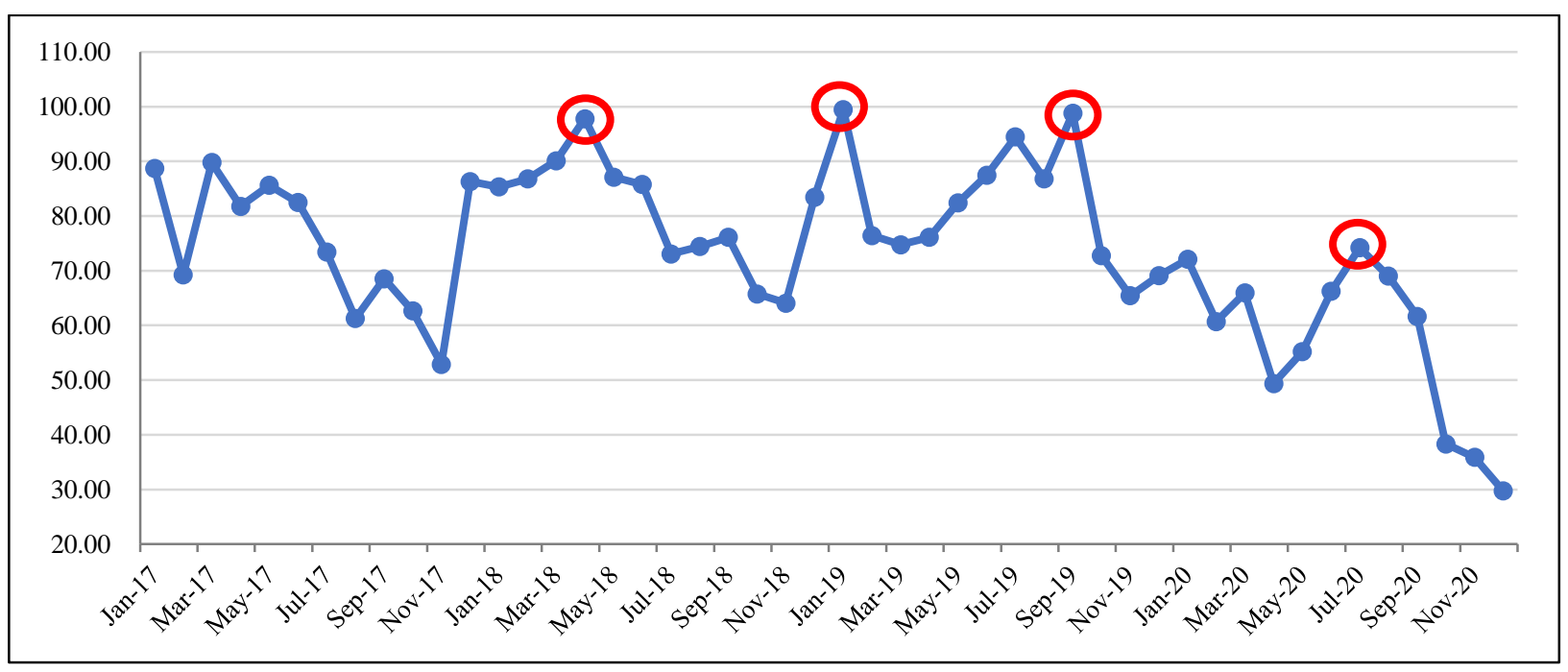

Figure 2. The rate of food poisoning incidence per 100,000 elderly people in Khon Kaen Province at 4 epidemic peaks selected for the model analyses. 


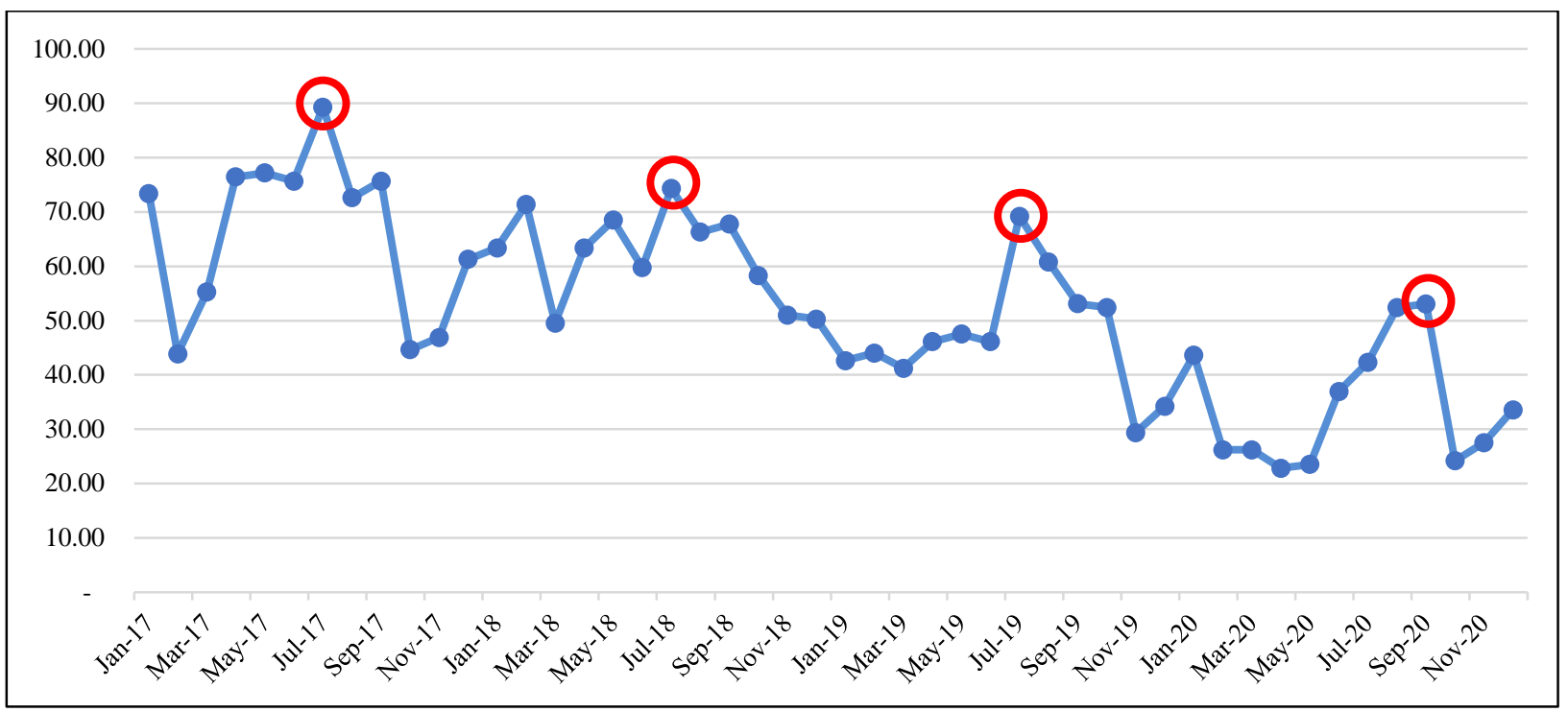

Figure 3. The rate of food poisoning incidence per 100,000 elderly people in Maha Sarakham Province at 4 epidemic peaks selected for the model analyses.

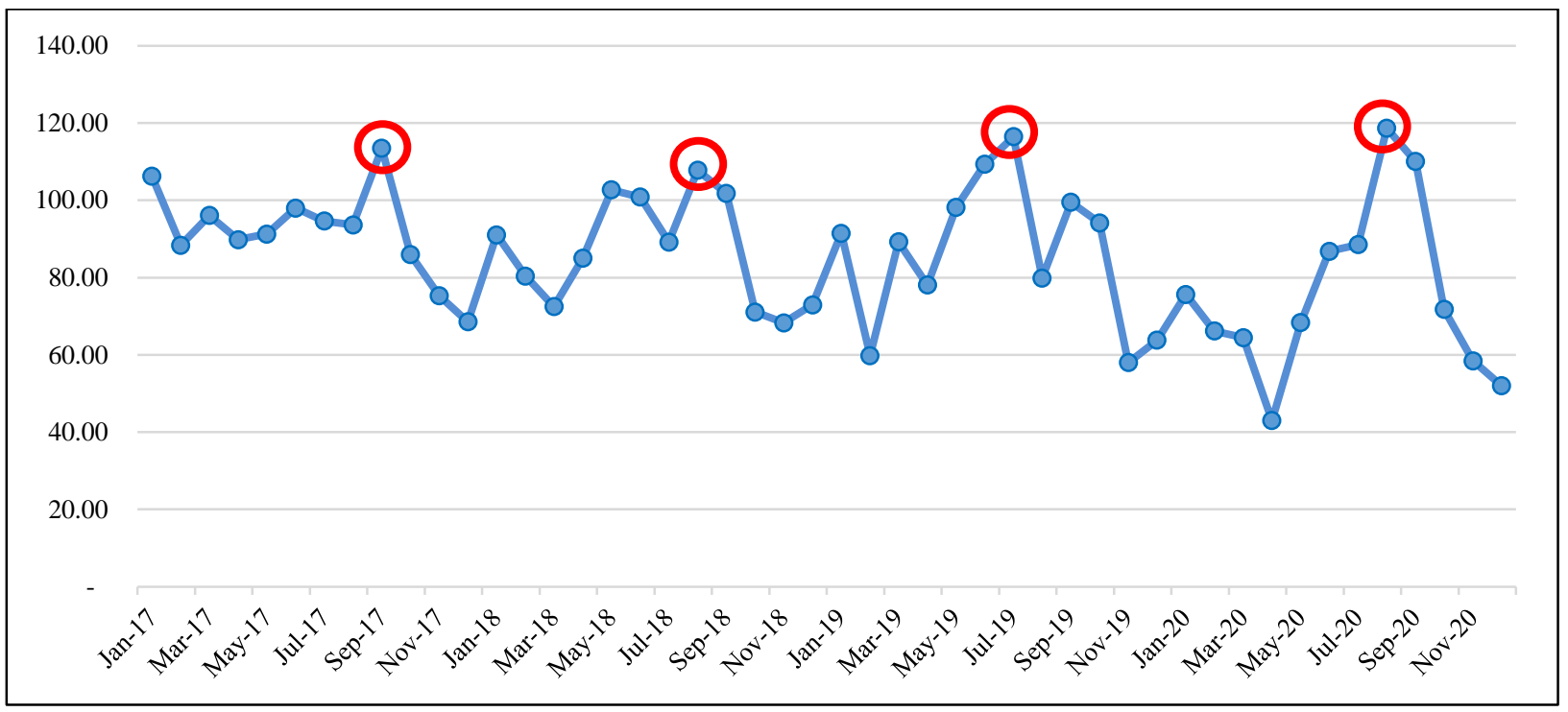

Figure 4. The rate of food poisoning incidence per 100,000 elderly people in Roi Et Province at 4 epidemic peaks selected for the model analyses.

Figures 2 to 4 illustrate the rate of food poisoning incidence per 100,000 elderly people at 4 selected epidemic peaks . The data used were in: April 2018, January 2019, September 2019, and July 2020 in Khon Kaen Province; in July 2017, July 2018, July 2019, and September 2020 in Maha Sarakham Province; and in September 2017, August 2018, July 2019, and August 2020 in Roi Et Province. These data were analyzed to obtain the forecasting models of GM(1,1) and DGM in each province, and the results are shown in Table 3 .The values of forecasting and relative errors of GM(1,1) and DGM in each province are shown in Table 4, whereas the results from the model accuracy testing of GM)1,1 (and DGM in each province are shown in Table 5.

Table 3. Forecasting model of GM(1,1) and DGM.

\begin{tabular}{|c|c|c|c|}
\hline Province & $X^{(0)}$ & GM(1,1) & DGM \\
\hline Khon Kaen & $X^{(0)}=\left(\begin{array}{llll}16 & 25 & 33 & 43\end{array}\right)$ & $\hat{x}^{(0)}(k+1)=19.05288 e^{0.26838 k}$ & $\hat{x}^{(0)}(k+1)=(25.09098)\left(1.30996^{k-1}\right)$ \\
\hline Maha Sarakham & $X^{(0)}=\left(\begin{array}{llll}7 & 19 & 31 & 45\end{array}\right)$ & $\hat{x}^{(0)}(k+1)=12.95167 e^{0.40908 k}$ & $\hat{x}^{(0)}(k+1)=(19.85976)\left(1.51334^{k-1}\right)$ \\
\hline Roi Et & $X^{(0)}=\left(\begin{array}{llll}9 & 20 & 31 & 44\end{array}\right)$ & $\hat{x}^{(0)}(k+1)=13.92074 e^{0.37839 k}$ & $\hat{x}^{(0)}(k+1)=(19.85976)\left(1.46618^{k-1}\right)$ \\
\hline
\end{tabular}


Table 4. The values of forecasting and relative errors of $\operatorname{GM}(1,1)$ and DGM.

\begin{tabular}{|c|c|c|c|c|c|c|}
\hline \multirow{2}{*}{ Province } & \multirow{2}{*}{$X^{(0)}$} & \multirow{2}{*}{$\begin{array}{c}\text { Original } \\
\text { (month) }\end{array}$} & \multicolumn{2}{|c|}{$\operatorname{GM}(1,1)$} & \multicolumn{2}{|c|}{ DGM } \\
\hline & & & Forecast (month) & Relative errors & Forecast (month) & Relative errors \\
\hline \multirow{4}{*}{ Khon Kaen } & $x^{(0)}(1)$ & 16 & - & - & - & - \\
\hline & $x^{(0)}(2)$ & 25 & 24.91817 & 0.00327 & 25.09098 & 0.00364 \\
\hline & $x^{(0)}(3)$ & 33 & 32.58905 & 0.01245 & 32.86830 & 0.00399 \\
\hline & $x^{(0)}(4)$ & 43 & 42.62135 & 0.00881 & 43.05630 & 0.00131 \\
\hline \multirow{4}{*}{ Maha Sarakham } & $x^{(0)}(1)$ & 7 & - & - & - & - \\
\hline & $x^{(0)}(2)$ & 19 & 19.49778 & 0.02620 & 19.85976 & 0.04525 \\
\hline & $x^{(0)}(3)$ & 31 & 29.35246 & 0.05315 & 30.05464 & 0.03050 \\
\hline & $x^{(0)}(4)$ & 45 & 44.18795 & 0.01805 & 45.48301 & 0.01073 \\
\hline \multirow{4}{*}{ Roi Et } & $x^{(0)}(1)$ & 9 & - & - & - & - \\
\hline & $x^{(0)}(2)$ & 20 & 20.32337 & 0.01617 & 20.63377 & 0.03169 \\
\hline & $x^{(0)}(3)$ & 31 & 29.67080 & 0.04288 & 30.25280 & 0.02410 \\
\hline & $x^{(0)}(4)$ & 44 & 43.31744 & 0.01551 & 44.35600 & 0.00809 \\
\hline
\end{tabular}

Table 5. The model accuracy testing of GM(1,1) and DGM.

\begin{tabular}{|c|c|c|c|c|c|}
\hline Province & Model & $\begin{array}{c}\text { Mean relative error } \\
(\bar{\Delta})\end{array}$ & $\begin{array}{c}\text { Degree of incidence } \\
(\varepsilon)\end{array}$ & $\begin{array}{c}\text { Variance ratio } \\
(c)\end{array}$ & $\begin{array}{c}\text { Small error probability } \\
(p)\end{array}$ \\
\hline \multirow{3}{*}{ Khon Kaen } & $\mathrm{GM}(1,1)$ & $\begin{array}{l}00818.0 \\
\left(1^{\text {st }} \text { level }\right)\end{array}$ & $\begin{array}{l}84909.0 \\
\left(2^{\text {nd }} \text { level }\right)\end{array}$ & $\begin{array}{l}01804.0 \\
\left(1^{\text {st }} \text { level }\right)\end{array}$ & $\begin{array}{c}1 \\
\left(1^{\text {st }} \text { level }\right)\end{array}$ \\
\hline & DGM & $\begin{array}{c}00298.0 \\
\left(1^{\text {st }} \text { level }\right)\end{array}$ & $\begin{array}{l}99985.0 \\
\left(1^{\text {st }} \text { level }\right)\end{array}$ & $\begin{array}{l}00851.0 \\
\left(1^{\text {st }} \text { level }\right)\end{array}$ & $\begin{array}{c}1 \\
\left(1^{\text {st }} \text { level }\right)\end{array}$ \\
\hline & \multicolumn{5}{|c|}{$\begin{array}{l}\text { The best model is DGM. } \\
\qquad \hat{x}^{(0)}(5)=56.40223\end{array}$} \\
\hline \multirow{3}{*}{ Maha Sarakham } & $\operatorname{GM}(1,1)$ & $\begin{array}{l}00032.0 \\
\left(1^{\text {st }} \text { level }\right)\end{array}$ & $\begin{array}{l}96670.0 \\
\left(1^{\text {st }} \text { level }\right)\end{array}$ & $\begin{array}{l}05784.0 \\
\left(1^{\text {st }} \text { level }\right)\end{array}$ & $\begin{array}{c}1 \\
1^{\text {st }} \text { level) }\end{array}$ \\
\hline & DGM & $\begin{array}{c}00029.0 \\
\left(1^{\text {st }} \text { level }\right)\end{array}$ & $\begin{array}{l}99735.0 \\
\left(1^{\text {st }} \text { level }\right)\end{array}$ & $\begin{array}{c}04793.0 \\
\left(1^{\text {st }} \text { level }\right)\end{array}$ & $\begin{array}{c}1 \\
\left(1^{\text {st }} \text { level }\right)\end{array}$ \\
\hline & \multicolumn{5}{|c|}{$\begin{array}{l}\text { The best model is DGM. } \\
\hat{x}^{(0)}(5)=68.83143\end{array}$} \\
\hline \multirow{3}{*}{ Roi Et } & $\operatorname{GM}(1,1)$ & $\begin{array}{l}00025.0 \\
\left(1^{\text {st }} \text { level }\right)\end{array}$ & $\begin{array}{l}99061.0 \\
\left(1^{\text {st }} \text { level }\right)\end{array}$ & $\begin{array}{l}04910.0 \\
\left(1^{\text {st }} \text { level }\right)\end{array}$ & $\begin{array}{c}1 \\
\left(1^{\text {st }} \text { level }\right)\end{array}$ \\
\hline & DGM & $\begin{array}{c}00021.0 \\
\left(1^{\text {st }} \text { level }\right)\end{array}$ & $\begin{array}{l}99824.0 \\
\left(1^{\text {st }} \text { level }\right)\end{array}$ & $\begin{array}{l}03988.0 \\
\left(1^{\text {st }} \text { level }\right)\end{array}$ & $\begin{array}{c}1 \\
\left(1^{\text {st }} \text { level }\right)\end{array}$ \\
\hline & \multicolumn{5}{|c|}{$\begin{array}{c}\text { The best model is DGM. } \\
\hat{x}^{(0)}(5)=65.03383\end{array}$} \\
\hline
\end{tabular}

In this study, the incidence rate of food poisoning of elderly people was conducted in Khon Kaen Province, Maha Sarakham Province and Roi Et Province which are located in the Northeastern region of Thailand. It was found that the 4 epidemic peaks of food poisoning incidence rate of elderly people in Maha Sarakham Province and Roi Et Province occurred from July to September, which is during the rainy season. In Khon Kaen Province, 4 epidemic peaks of food poisoning incidence rate of elderly people occurred in April 2018, January 2019, September 2019, and July 2020. It is shown that the first epidemic peak occurred during the summer season and tends to occur during the rainy season. The rainy season of Thailand is tropical and the pathogens may be growing as well. If people are not careful when eating, it may result in gastrointestinal diseases such as food poisoning, especially in the elderly people with low immunity, it can lead to death. In this research, the GM(1,1) model and the DGM model were used to construct the grey disaster model. The simulation results showed that the DGM model had a better performance. Then, the DGM model was chosen to make the prediction, which is corresponding to Shen et al. [5].

\section{4- Conclusion}

Grey disaster prediction, the GM(1,1) and DGM, is important to predict the time of abnormal values, and propose the forecast of the exact times of forthcoming disasters to prepare ahead of time for the worst situation. In this study, the $\mathrm{GM}(1,1)$ and DGM were used for forecasting the epidemic peaks of food poisoning incidence in the elderly people in Khon Kaen Province, Maha Sarakham Province, and Roi Et Province in Thailand .The study found that the DGM had 
higher forecasting effectiveness than that of the $\mathrm{GM}(1,1)$ in all three provinces .When the DGM is used in forecasting, the forecasting value in Khon Kaen Province was found at $\hat{x}^{(0)}(5)=56.40223$, meaning that food poisoning incidence would re-emerge in elderly people from August to September 2021 and the mean relative error of the DGM model is $0.298 \%$.In Maha Sarakham Province, the forecasting value was found at $\hat{x}^{(0)}(5)=68.83143$, meaning that food poisoning incidence would re-emerge in elderly people from August to September 2022 and the mean relative error of the DGM model is $0.029 \%$. In addition, the forecasting value in Roi Et Province was found at $\hat{x}^{(0)}(5)=65.03383$, meaning that food poisoning incidence would re-emerge in elderly people from May to June 2022 and the mean relative error of the DGM model is $0.021 \%$. Although the forecasting with Grey theory is highly effective and has yielded good results, it may not be appropriate for all situations. Moreover, the forecasting with Grey theory is more accurate in the short term but its accuracy in long-term forecasting may decrease [24]. Therefore, we should consider and analyze the actual situation and select a suitable model and adapt it to the situation of the disease. This makes it possible to take full advantage of forecasting models to maximize long-term benefits.

\section{5- Declarations}

\section{5-1-Author Contributions}

Conceptualization, N.C., P.G., B.K. and M.C.; methodology, M.C.; software, M.C.; validation, P.G. and B.K.; formal analysis, M.C.; investigation, B.K. and M.C.; resources, N.C. and P.G.; data curation, N.C., P.G. and P.B.; writing original draft preparation, N.C.; writing - review and editing, B.K.; visualization, P.B.; corresponding author, M.C.; project administration, N.C.; funding acquisition, N.C. All authors have read and agreed to the published version of the manuscript.

\section{5-2-Data Availability Statement}

The data presented in this study are available on request from the corresponding author.

\section{5-3- Funding}

This research project was financially supported by Thailand Science Research and Innovation Fund (TSRI) 2021 and Mahasarakham University.

\section{5-4-Acknowledgements}

This research project was financially supported by Thailand Science Research and Innovation Fund (TSRI) 2021 and Mahasarakham University. The authors would like to thank the associate editor and the referees.

\section{5-5- Conflicts of Interest}

The authors declare that there is no conflict of interests regarding the publication of this manuscript. In addition, the ethical issues, including plagiarism, informed consent, misconduct, data fabrication and/or falsification, double publication and/or submission, and redundancies have been completely observed by the authors.

\section{6- References}

[1] Ju-Long, Deng. “Control Problems of Grey Systems.” Systems and Control Letters 1, no. 5 (1982): 288-94. doi:10.1016/S01676911(82)80025-X.

[2] Ju-Long, Deng. "Introduction to grey system theory." The Journal of grey system 1, no. 1 (1989): 1-24.

[3] Xie, Nai ming, and Si feng Liu. "Discrete Grey Forecasting Model and Its Optimization.” Applied Mathematical Modelling 33, no. 2 (2009): 1173-86. doi:10.1016/j.apm.2008.01.011.

[4] Lin, Wei Zhong, Jian An Fang, Xuan Xiao, and Kuo Chen Chou. "IDNA-Prot: Identification of DNA Binding Proteins Using Random Forest with Grey Model.” PLoS ONE 6, no. 9 (2011): 24756. doi:10.1371/journal.pone.0024756.

[5] Shen, Xuejun, Limin Ou, Xiaojun Chen, Xin Zhang, and Xuerui Tan. "The Application of the Grey Disaster Model to Forecast Epidemic Peaks of Typhoid and Paratyphoid Fever in China.” PLoS ONE, 2013. doi:10.1371/journal.pone.0060601.

[6] Nsoesie, Elaine O., Madhav Marathe, and John S. Brownstein. "Forecasting Peaks of Seasonal Influenza Epidemics.” PLoS Currents 5, no. Outbreaks (2013). doi:10.1371/currents.outbreaks.bb1e879a23137022ea79a8c508b030bc.

[7] Kuniya, Toshikazu. "Prediction of the Epidemic Peak of Coronavirus Disease in Japan, 2020." Journal of Clinical Medicine 9, no. 3 (2020): 789. doi:10.3390/jcm9030789.

[8] Ceylan, Zeynep. "Short-Term Prediction of COVID-19 Spread Using Grey Rolling Model Optimized by Particle Swarm Optimization.” Applied Soft Computing 109 (2021). doi:10.1016/j.asoc.2021.107592. 
[9] Saxena, Akash. "Grey Forecasting Models Based on Internal Optimization for Novel Corona Virus (COVID-19).” Applied Soft Computing 111 (2021): 107735. doi:10.1016/j.asoc.2021.107735.

[10] Hsu, Li Chang. "Applying the Grey Prediction Model to the Global Integrated Circuit Industry." Technological Forecasting and Social Change 70, no. 6 (2003): 563-74. doi:10.1016/S0040-1625(02)00195-6.

[11] Hsu, Che Chiang, and Chia Yon Chen. "Applications of Improved Grey Prediction Model for Power Demand Forecasting." Energy Conversion and Management 44, no. 14 (2003): 2241-49. doi:10.1016/S0196-8904(02)00248-0.

[12] Li, J, B Y Wang, and B S Zhang. “Application of Improved Grey Prediction Model to Petroleum Cost Forecasting." Petroleum Science 3 (2006): 89-92.

[13] Tsai, Chen Fang. "The Application of Grey Theory to Taiwan Pollution Prediction." In Lecture Notes in Engineering and Computer Science, 2198:731-36, 2012.

[14] Ene, Seval, and Nursel Öztürk. "Grey Modelling Based Forecasting System for Return Flow of End-of-Life Vehicles." Technological Forecasting and Social Change 115 (2017): 155-66. doi:10.1016/j.techfore.2016.09.030.

[15] Yuan, Chaoqing, Yuxin Zhu, Ding Chen, Sifeng Liu, and Zhigeng Fang. "Using the GM(1,1) Model Cluster to Forecast Global Oil Consumption.” Grey Systems: Theory and Application 7, no. 2 (2017): 286-96. doi:10.1108/gs-01-2017-0001.

[16] Wang, Zheng Xin, Qin Li, and Ling Ling Pei. "Grey Forecasting Method of Quarterly Hydropower Production in China Based on a Data Grouping Approach.” Applied Mathematical Modelling 51 (2017): 302-16. doi:10.1016/j.apm.2017.07.003.

[17] Wang, Qianru, Li Liu, Shu Wang, Jian Zhou Wang, and Ming Liu. "Predicting Beijing's Tertiary Industry with an Improved Grey Model.” Applied Soft Computing 57 (2017): 482-94. doi:10.1016/j.asoc.2017.04.022.

[18] Ding, Song, Keith W. Hipel, and Yao guo Dang. "Forecasting China's Electricity Consumption Using a New Grey Prediction Model.” Energy 149 (2018): 314-28. doi:10.1016/j.energy.2018.01.169.

[19] Li, Menglu, Wei Wang, Gejirifu De, Xionghua Ji, and Zhongfu Tan. "Forecasting Carbon Emissions Related to Energy Consumption in Beijing-Tianjin-Hebei Region Based on Grey Prediction Theory and Extreme Learning Machine Optimized by Support Vector Machine Algorithm.” Energies 11, no. 9 (2018): 2475-2489. doi:10.3390/en11092475.

[20] Luo, Dang, Xiaolei Wang, Decai Sun, and Guozheng Zhang. "Discrete Grey DGM(1,1,T) Model with Time Periodic Term and Its Application.” Xitong Gongcheng Lilun Yu Shijian/System Engineering Theory and Practice 40, no. 10 (2020): $2737-46$. doi:10.12011/1000-6788-2019-1335-10.

[21] Wu, Lifeng, and Hongying Zhao. "Discrete Grey Model with the Weighted Accumulation." Soft Computing 23, no. 23 (2019): 12873-81. doi:10.1007/s00500-019-03845-3.

[22] Guo, Hua, Shengxiang Deng, Jinbiao Yang, Jiangwei Liu, and Changda Nie. "Analysis and Prediction of Industrial Energy Conservation in Underdeveloped Regions of China Using a Data Pre-Processing Grey Model.” Energy Policy 139 (2020): 111244. doi:10.1016/j.enpol.2020.111244.

[23] Cao, Yun, Kedong Yin, Xuemei Li, and Chenchen Zhai. "Forecasting CO2 Emissions from Chinese Marine Fleets Using Multivariable Trend Interaction Grey Model.” Applied Soft Computing 104 (2021): 107220. doi:10.1016/j.asoc.2021.107220.

[24] Ding, Fan, Dante S. Zarlenga, Yudong Ren, Guangxing Li, Jin Luan, and Xiaofeng Ren. "Use of the D-R Model to Define Trends in the Emergence of Ceftazidime-Resistant Escherichia Coli in China." PLoS ONE 6, no. 12 (2011): 27295. doi:10.1371/journal.pone.0027295. 